\title{
BCR: a new target in resistance mediated by BCR/ABL-315I?
}

\author{
Isabella Haberbosch ${ }^{1}$, Anahita Rafiei ${ }^{4}$, Claudia Oancea ${ }^{2}$, Oliver Gerhart Ottmann ${ }^{2,3}$, \\ Martin Ruthardt ${ }^{2}$ and Afsar Ali Mian ${ }^{2}$ \\ ${ }^{1}$ Department of Hematology, Goethe University, Frankfurt, Germany \\ 2 Deparment of Haematology, School of Medicine, Cardiff University, Cardiff, United Kingdom \\ ${ }^{3}$ Cardiff Experimental Cancer Medicine Centre (ECMC), Cardiff, United Kingdom \\ ${ }^{4}$ Department of Hematology, University of Zurich, Zurich, Switzerland \\ Correspondence to: Afsar Ali Mian, email: MianA@cardiff.ac.uk
}

Martin Ruthardt, email: RuthardtM@cardiff.ac.uk

Keywords: Philadelphia chromosome-positive leukemia, BCR/ABL, resistant mutation T315l, endogenous BCR

Received: November 18, $2015 \quad$ Accepted: January 20, 2016

Published: February 08, 2016

\section{ABSTRACT}

Targeting BCR/ABL with Tyrosine kinase inhibitors (TKIs) is a proven concept for the treatment of Philadelphia chromosome-positive $(\mathrm{Ph}+)$ leukemias but the "gatekeeper"mutation T315I confers resistance against all approved TKIs, with the only exception of ponatinib, a multi-targeted kinase inhibitor. Besides resistance to TKIs, T315I also confers additional features to the leukemogenic potential of BCR/ $A B L$, involving endogenous $B C R$. Therefore we studied the role of $B C R$ on $B C R / A B L$ mutants lacking functional domains indispensable for the oncogenic activity of $B C R$ / $A B L$. We used the factor independent growth of murine myeloid progenitor $32 \mathrm{D}$ cells and the transformation of Rat-1 fibroblasts both mediated by BCR/ABL. Here we report that $\mathrm{T} 315 \mathrm{I}$ restores the capacity to mediate factor-independent growth and transformation potential of loss-of-function mutants of BCR/ABL. Targeting endogenous Bcr abrogated the capacity of oligomerization deficient mutant of BCR/ ABL-T315I to mediate factor independent growth of 32D cells and strongly reduced their transformation potential in Rat-1 cells, as well as led to the up-regulation of mitogen activated protein kinase (MAPK) pathway.

Our data show that the T315I restores the capacity of loss-of-function mutants to transform cells which is dependent on the transphosphorylation of endogenous Bcr, which becomes a putative therapeutic target to overcome resistance by T315I.

\section{INTRODUCTION}

The fine regulation of $\mathrm{ABL}$ kinase is lost by its fusion to $\mathrm{BCR}$ in the context of the $\mathrm{t}(9 ; 22)$. The constitutive activation of the ABL-kinase activity induces aberrant proliferation and neoplastic transformation by constitutive activation of down-stream signaling pathways such as RAS, PI3 kinase, or STATs [1, 2]. Several animal models proved that $\mathrm{BCR} / \mathrm{ABL}$ is responsible for the induction of the leukemic phenotype related to the $t(9 ; 22)$ [3-6].

The inhibition of aberrant BCR/ABL kinase activity by selective ATP mimetics (TKI) such as imatinib, dasatinib or nilotinib, is a valid concept of causal therapy for $\mathrm{Ph}+$ leukemia [7-11]. Unfortunately in advanced $\mathrm{Ph}+$ leukemia, CML-blast crisis and $\mathrm{Ph}+\mathrm{ALL}$, these TKI select resistant clones, mostly due to the presence of point mutations in BCR/ABL $[12,13]$. With the exception of the "gatekeeper" mutation T315I the clinically most relevant mutations which confer resistance against the first generation TKI imatinib are targeted by one of the second generation TKI, dasatinib or nilotinib [14].

The "gatekeeper" mutation T315I confers not only resistance against these ATP-competitors but also against some allosteric inhibitor, such as GNF-2 or against inhibition of oligomerization [15-18]. The only approved exception is the multi-targeted kinase inhibitor ponatinib [19-21]. Other TKIs, such as PF-114, able to target BCR/ $\mathrm{ABL}$ harboring the T315I are actually in pre-clinical development [6].

The mechanisms by which T315I confers resistance to TKI were mainly attributed to an alteration of the three- 
dimensional structure of the ATP-binding site, leading to a loss of a fundamental $\mathrm{H}$ bond [22-25]. Molecular dynamics simulations on the interactions between BCR/ ABL-T315I and imatinib revealed that in addition to the supposedly critical H-bond, also other protein/drug interactions are drastically and unfavorably changed in a sort of "domino effect" primarily induced by the T315I [26]. Additional conformational changes due to the T315I and the other resistance mutants further lead to i.) a steric hindrance for binding the TKIs; ii.) changes in the overall ABL kinase activity and iii.) modified biological activity as compared to the unmutated $\mathrm{BCR} / \mathrm{ABL}[27,28]$.

The key event for the activation of the $\mathrm{BCR} / \mathrm{ABL}$ kinase is the tetramerization mediated by the N-terminal coiled coil (CC) region of the BCR-portion [29, 30]. Accordingly, targeting the $\mathrm{CC}$-domain forces $\mathrm{BCR} /$ $\mathrm{ABL}$ into a monomeric conformation, abolishes its transformation potential by interfering with its kinase activity and increases sensitivity to imatinib $[17,18,29$, $30]$. Tetramerization deficient mutants ( $\triangle \mathrm{CC}-\mathrm{BCR} / \mathrm{ABL})$ exhibit decreased TK-activity, resulting in a reduced capacity to mediate factor dependent growth in $\mathrm{Ba} / \mathrm{F} 3$ cells and the suppression of the transformation potential of BCR/ABL [29, 30].

Noteworthy factor independent growth was suppressed by the inhibition of tetramerization in hematopoietic progenitors expressing $\mathrm{BCR} / \mathrm{ABL}$ harboring the $\mathrm{Y} 253 \mathrm{~F}$ and $\mathrm{E} 255 \mathrm{~K}$ mutations but not the T315I mutation $[17,28]$. In fact T315I restores oncogenic activity of BCR/ABL not only in tetramerization deficient but also in other loss-of-function mutants. This biological activity seems to be related to the transphosphorylation of endogenous BCR [28].

In order to further confirm the role of the endogenous BCR for the mediation of resistance mediated by the T315I we investigated further the effect of T315I on the transformation potential and the capacity to mediate factor independent growth of $\mathrm{BCR} / \mathrm{ABL}$ mutants lacking functional domains in the BCR portion considered indispensable for the oncogenic activity of BCR/ABL.

\section{RESULTS}

\section{T315I restores capacity to mediate factor independent growth of loss of function mutants of $\mathrm{p}^{185^{B C R / A B L}}$ in 32D cells}

Targeting oligomerization either by competitive peptides or by deleting the CC-domain efficiently interferes with the transformation potential of native $\mathrm{p} 185^{B C R / A B L}$ but not of $\mathrm{p} 185-\mathrm{T} 315 \mathrm{I}^{\mathrm{BCR} / \mathrm{ABL}}$. This strongly suggests that the "gatekeeper" mutation T315I is not only responsible for TKI-resistance, but also confers additional properties to $\mathrm{BCR} / \mathrm{ABL}$ which is uncovered in the case of a loss of oligomerization.

To further disclose the influence of T315I on the biology of $\mathrm{BCR} / \mathrm{ABL}$ we investigated the effects of T315I on "loss of function mutants" of BCR/ABL, unable to mediate factor independent growth of murine hematopoietic progenitors. The schematic representation of the mutants used in this study is shown in Figure 1. We retrovirally infected $32 \mathrm{D}$ cells with the constructs and studied their effects on factor independent growth. Native p185 18 BCR/ABL was used as a control.

The phosphorylation at Y177 is indispensable for the function of BCR/ABL. To investigate the effects of T315I on a mutant defective in phosphorylation at Y177 we used p185-T315I-Y177F in which Y177 was mutated to phenylalanine. As shown in Figure 1A, the Y177F reduced factor independent growth of 32D cells mediated by $\mathrm{p} 185^{\mathrm{BCR} / \mathrm{ABL}}$, which was completely restored by the presence of T315I.

Next we focused on the influence of T315I on BCR/ ABL with deficiencies in oligomerization. As reported in Figure 1B, the presence of T315I restored the capacity of $\triangle \mathrm{CC}-\mathrm{p} 185$ to mediate factor independent growth as shown by the fact that $\triangle \mathrm{CC}$-p185-T315I had the identical growth rate as native $\mathrm{p} 185^{\mathrm{BCR} / \mathrm{ABL}}$ (Figure $1 \mathrm{~B}$ ).

In order to confirm that both oligomerization interface and Y177 phosphorylation site are dispensable for the function of T315I, we used a combined mutant $\triangle \mathrm{CCp} 185-\mathrm{Y} 177 \mathrm{~F}$ - lacking both the CC oligomerization interface and the phosphorylation site at Y177. Even in this mutant, which lacks two functions considered to be indispensable for the activity of $\mathrm{BCR} / \mathrm{ABL}$ and whose deletion abolished factor independent growth, T315I restored the capacity to confer factor independent growth (Figure 1C).

To disclose the significance of the the serine/ threonine $(\mathrm{S} / \mathrm{T})$ domain of $\mathrm{BCR}$ we investigated the effects of T315I on the factor independent growth of 32D cells expressing a p185 $5^{B C R / A B L}$ construct in which the entire $\mathrm{S} / \mathrm{T}$ domain was deleted with or without the T315I. The deletion of S/T domain attenuated the factor independent growth of $32 \mathrm{D}$ cells mediated by $\mathrm{p} 185^{B C R / A B L}$, which was restored by the presence of T315I to the level of native p185 $5^{B C R / A B L}$ (Figure 1D).

For the restoration of factor independent growth, T315I seems to need at least parts of the BCR portion as shown by the fact that it was unable to confer factor independence to the ABL-portion of $185^{B C R / A B L}$ (\#ABL) (Figure 1E).

Taken together, these data indicate that the "gatekeeper" mutation T315I confers additional properties to the loss of function mutants of $\mathrm{p} 185^{B C R / A B L}$, which allow to restore the capacity to mediate factor independence in $32 \mathrm{D}$ cells. 


\section{The T315I influences transformation potential of $\mathrm{p}^{185^{B C R / A B L}}$ loss of function mutants}

Factor independent growth of 32D cells stands for the substitution of the IL-3 signaling by an alternative survival signal, which can be mediated by activated kinases such as BCR/ABL. To investigate the influence of T315I on the transformation potential of loss-of function mutants of $\mathrm{p} 185^{\mathrm{BCR} / \mathrm{ABL}}$, we performed classical transformation assays in order to study both the loss of contact inhibition and anchorage-dependent growth in retrovirally transduced Rat-1 fibroblasts, by focus and colony formation assays, respectively.

The abolition of the Y177 phosphorylation site did not influence the lack of contact inhibition of $\mathrm{p} 185^{B C R / A B L}$ expressing Rat-1 cells (Figure 2A), but it abolished their ancorage-independent growth, which was restored, even if not completely, by the presence of T315I (Figure 2B).

Targeting oligomerization by the deletion of the CCdomain completely abolished contact inhibition as well as anchorage-dependent growth of $\mathrm{p} 185^{B C R / A B L}$, but both were restored by the T315I as shown by the focus and colony formation (Figures 2A and 2B).

The deletion of $\mathrm{S} / \mathrm{T}$ alone in the $\Delta \mathrm{S} / \mathrm{T}-\mathrm{p} 185^{B C R / A B L}$ in combination with the point mutation Y177F interfered with the transformation potential of $\mathrm{p} \mathrm{p} 185^{B C R / A B L}$ (Figure $2 \mathrm{~A}$ and $2 \mathrm{~B}$ ). The T315I did not apparently influence the already full transformation potential of $\Delta \mathrm{S} / \mathrm{T}-\mathrm{p} 185^{\mathrm{BCR} / \mathrm{ABL}}$ but "partially" restored colony formation but not focus formation of the $\Delta$ S/T-p185-Y177F (Figure 2A and 2B).

As already shown for the factor independent growth T315I was not able to re-establish transformation potential of the isolated \#ABL (Figure 2A and 2B).

These data show that T315I is able to influence not only the factor-independent growth of loss of function mutants of $\mathrm{p} 185^{B C R / A B L}$, but also their transformation potential, even if in a different manner as compared to its effect on factor independent growth. Furthermore these data suggest, that the presence of the phosphorylation

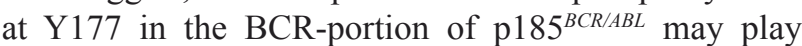
an important role for the capacity of T315I to mediate transformation.

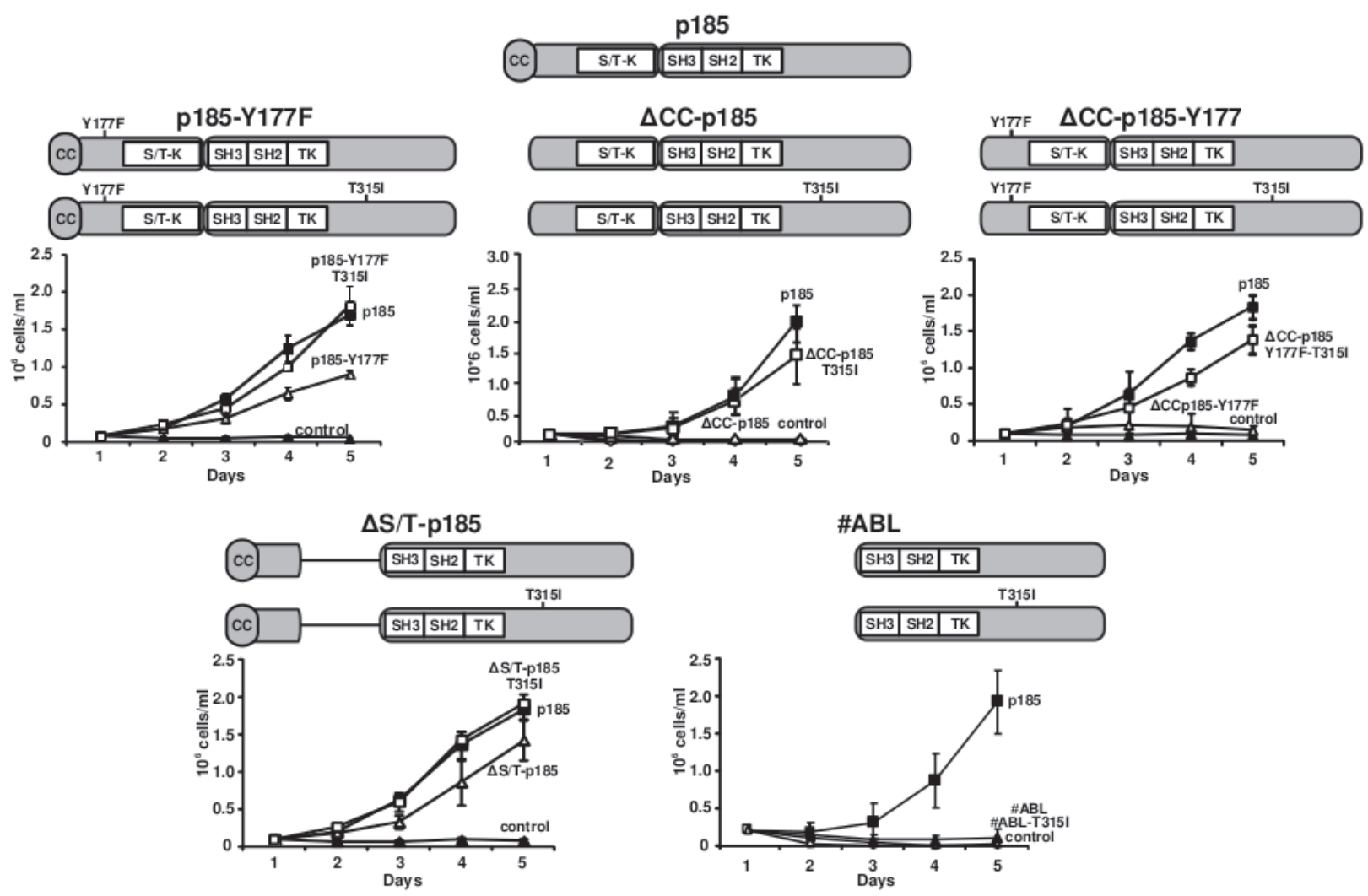

Figure 1: Restoration of factor independent growth of loss of function mutants of p185BCR/ABL by mutation T315I. Modular organization of the $185^{B C R A B L}$ mutants + - T315I. For the determination of factor-independent growth of loss of function mutatnts of $185^{B C R A B L}$ in the presence or absence of T315I mutation, 32D cells were retrovirally transduced with the indicated constructs. The number of viable cells was daily determined by Trypan blue dye-exclusion. The graphs show the means $+/$ SD of three independent experiments. A. $\mathrm{p} 185^{B C R A B L}$ mutants with a point mutation at $\mathrm{Y} 177$ (Y177F) +/- T315I. B. p185 ${ }^{B C R A B L}$ mutants lacking the CC oligomerization interface +/-T315I. C. p185 $5^{B C R A B L}$ lacking the N-terminal CC-domain together with a point mutation at the Y177 (Y177F) +/-T315I. D. $\Delta$ S/T-p185 mutants where the N-terminus of BCR comprising the CC-domain and the Y177 phosphorylation site fused to the ABL-portion of the fusion protein +/-T315I. E. \#ABL - the ABL-portion of the BCR/ABL fusion protein +/- T315I. 


\section{T315I restores Erk activation by loss of function mutants of $\mathbf{p}^{185^{B C R / A B L}}$}

We have recently shown that the capacity of T315I to restore factor independent growth to the loss of function mutants of $\mathrm{p} 185^{B C R / A B L}$ is accompanied by trans-phosphorylation of endogenous BCR at position Y177[28].

These differences between native $\mathrm{p} 185^{B C R / A B L}$ and $\mathrm{p} 185-\mathrm{T} 315 \mathrm{I}^{B C R / A B L}$ regarding the apparent importance of the trans-phosphorylation of BCR at Y177 for the resistance conferred by T315I prompted us to investigate the down-stream signaling in the presence or absence of T315I. Therefore, we transduced 32D cells with the indicated constructs. In order to avoid the bias of stress-related activation of signaling pathways these experiments were performed in the presence of IL-3. Erkactivation was assessed by a specific antibody directed against phosphorylated Erk1/2. We found that $\mathrm{p} 185^{B C R}$ ${ }_{A B L}$ and p $185-\mathrm{T} 315 \mathrm{I}^{B C R / A B L}$ fully activated Erk $1 / 2$ whereas the loss-of-function was accompanied by the loss of Erk1/2 activation (Figure 3A). T315I restored the Erk1/2 activation in all tested mutants of $\mathrm{p} 185^{B C R / A B L}$ with the exception of \#ABL, which was not able to exhibit either factor independent growth and or transformation (Figure 1 and Figure 2).

Activation of Stats is indispensable for the transformation potential and the factor independent growth mediated by $\mathrm{p} 185^{B C R A B L}$. Therefore we studied Stat5-activation in cells expressing $185^{B C R / A B L}$ mutants in the presence/absence of the T315I by using a specific antibody directed against phosphorylated Stat 5 . As shown in Figure 3B, in cells expressing p185 ${ }^{B C R A B L}$ or p185$\mathrm{T} 315 \mathrm{I}^{B C R / A B L}$ Stat5 was activated. The oligomerizationdeficient $\Delta C C$-p 185 was unable to activate, whereas Stat5 was fully activated in cells expressing $\Delta$ CC-p185-T315I.

Taken together, these data indicate that the biological effects of the T315I mutation may be mediated through aberrant signaling pathways in addition to transphosphorylation of endogenous BCR.

Endogenous BCR is indispensable for the reestablishment of the factor independent growth and transformation potential of oligomerization deficient $\Delta$ CC-p185-T315I

In order to further disclose the role of the transphosphorylation of endogenous BCR for the p185$\mathrm{T} 315 \mathrm{I}^{\mathrm{BCR} / \mathrm{ABL}}$ we used RNAi to target BCR. BCRexpression was targeted by specific shRNA in 32D cells expressing either p185-T315I ${ }^{B C R / A B L}$ or $\triangle C$ C-p185-T315I by lentiviral transduction. Efficacy of these shRNA to down-regulate endogenous $\mathrm{BCR}$ in these cells in comparison to a non-related control shRNA (NTC) is
A

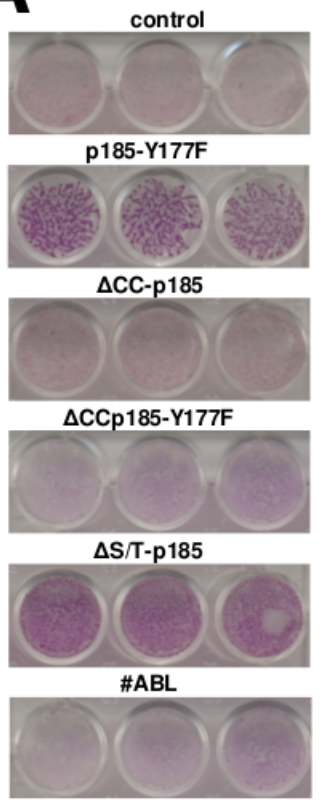

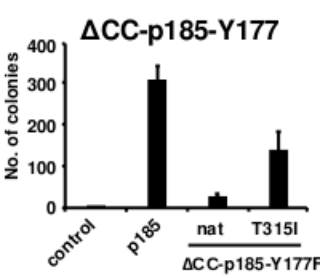

p185

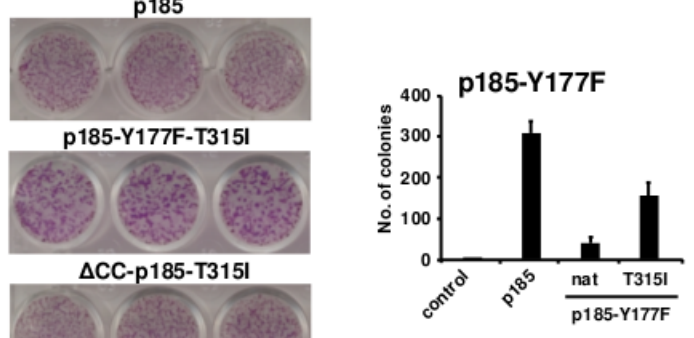

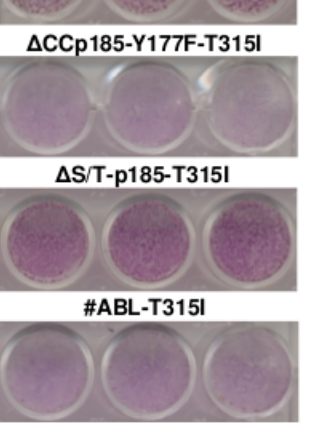

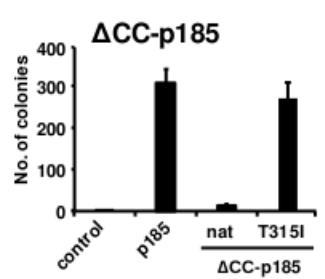

B

$\Delta$ CC-p185
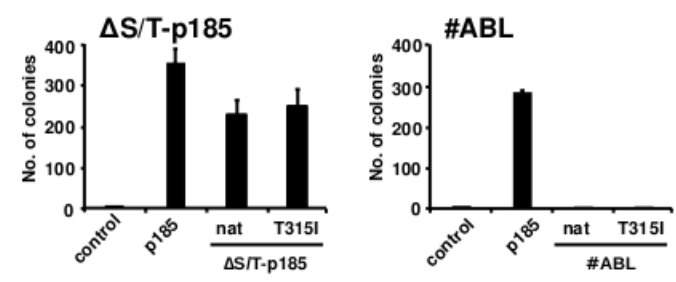

Figure 2: The influence of the resistance mutations on the transformation potential of loss of function mutants of p185BCR/ABL. A. Focus formation assay - 4x104 infected Rat-1 cells/well were plated in 24-well-plates, grown for $72 \mathrm{~h}$ to confluence, and incubated for additional 12 days. The plates were then washed, dried, and stained with crystal violet. One representative of each of 3 experiments performed in triplicate is given (34x magnification). B. Colony formation - Rat-1 cells were retrovirally transduced with the indicated constructs and seeded at $5 \times 10^{3}$ cells/well in soft-agar in 6-well-plates. After 15 days, the colonies were counted and the means $+/$ - SDS of triplicates of 2 representative experiments are given. 
shown in Figure 4A. Proliferation/cytotoxicity was assessed by a XTT assay. As reported in Figure 4B and $4 \mathrm{C}$, targeting of $\mathrm{BCR}$ did not have effect on the factor independent growth of cells expressing p185-T315I ${ }^{B C R}$ ${ }_{A B L}$, whereas it abrogated the capacity of $\triangle \mathrm{CC}-\mathrm{p} 185-$ T315I to mediate factor independent growth (Figure 4B and $4 \mathrm{C}$ ). The high apoptosis rate, measured by 7-AADstaining, indicated a loss of the capacity to mediate factor independent growth in the absence of endogenous Bcr (Figure 4C).

Next we investigated the possibility to interfere with the role of BCR in the transformation potential of $\mathrm{p} 185$ $\mathrm{T} 315 \mathrm{I}^{B C R / A B L}$ or $\triangle \mathrm{CC}-\mathrm{p} 185-\mathrm{T} 315 \mathrm{I}$. Thus we performed focus formation assays and colony assays on Rat-1 fibroblasts expressing p185-T315I ${ }^{\mathrm{BCR} / \mathrm{ABL}}$ or $\Delta \mathrm{CC}-\mathrm{p} 185-$ T315I lentivirally transduced with either NTC or shRNA against BCR.

As shown in Figures 5A, targeting of BCR attenuated focus and colony formation in Rat-1 cells expressing p185-T315I. In particular this effect was apparent by a reduction of the number but also of the size of the colonies in the semisolid medium. Noteworthy the transformation potential of $\triangle \mathrm{CC}$-p $185-\mathrm{T} 315 \mathrm{I}^{B C R / A B L}$ was nearly completely abolished (Figures 5B).

Taken together, these data indicate that targeting endogenous BCR with shRNA strongly reduced the transformation potential $\mathrm{p} 185-\mathrm{T} 315 \mathrm{I}^{B C R / A B L}$ and $\triangle \mathrm{CCp} 185$ T315I in Rat-1 cells.

To determine the role of BCR dependent signaling for the survival of cells expressing loss of function mutants of $\mathrm{p} 185^{B C R / A B L}$ in the presence of T315I upon factor withdrawal, we studied the effects of targeting BCR on the activation of Erk1/2 and Stat5 in cells expressing either p185-T315I ${ }^{B C R / A B L}$ or $\triangle$ CC-p185-T315I. Here we show that down-regulation of BCR was accompanied by the loss of Erk1/2 activation in both p185-T315I- and $\Delta \mathrm{CCp} 185-$ T315I-positive cells (Figure 4E).

In summary, these data strongly suggest that the endogenous BCR and its related signaling is indispensable for the capacity of T315I to restore transformation potential and the capacity to mediate factor independent growth of loss of function in mutants of $\mathrm{p} 185^{B C R / A B L}$.
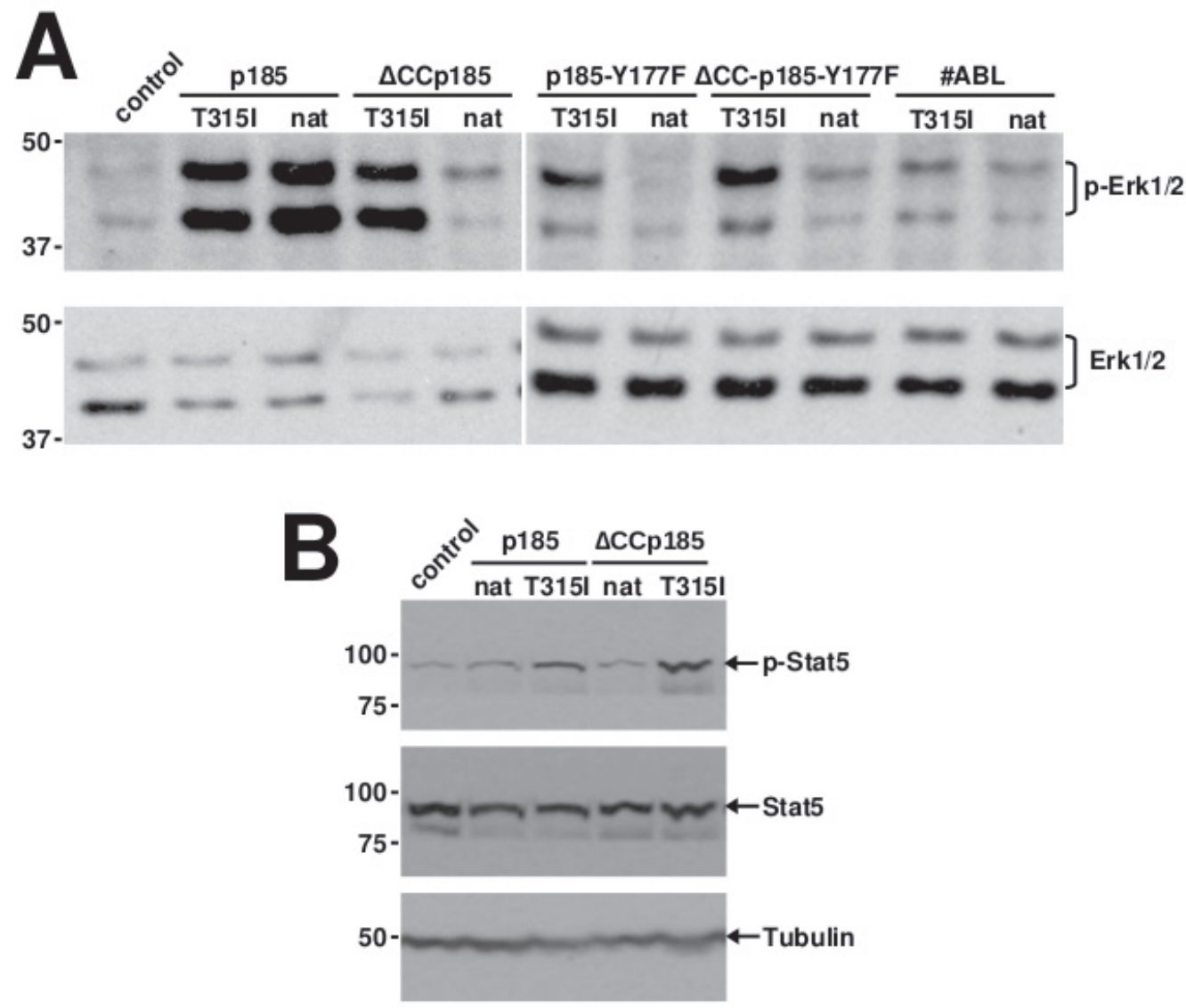

Figure 3: Restoration of aberrant activation of MAPK and Jak/STAT pathways in loss of function mutants of p185BCR/ABL by T315I. A. Western blotting on lysates of 32D cells expressing the indicated transgenes using antibodies directed against Erk1/2, phosphorylated Erk1/2. B. Western blotting on lysates of 32D cells expressing the indicated transgenes using antibodies directed against signal transducer and activator of transcription (STAT5) and phosphorylated STAT5. Molecular mass references (KDa) are given and Tubulin was used as a loading control. 


\section{DISCUSSION}

The aim of the study was to determine whether and how the the "gatekeeper" mutation T315I confers novel biological features to $\mathrm{BCR} / \mathrm{ABL}$ influencing its leukaemogenic potential.; (ii) to disclose role of the endogenous BCR for the new biological features determined by T315I in $185^{B C R A B L}$. We focused our experiments on the $185^{B C R / A B L}$ isoform, because it has been shown to behave exactly like the p $210^{B C R / A B L}$ in our cell model $[28,31,32]$.

$\mathrm{Ph}+$ leukemia, neither CML nor $\mathrm{Ph}+\mathrm{ALL}$, ever emerges with a full blown T315I-positive leukemia even if the clone with the mutation is already existing and detectable [33]. Therefore the mutation confers biological features to the clones unveiled by the treatment. One can hypothesize that the presence of the T315I confers a growth disadvantage with respect to native $\mathrm{BCR} / \mathrm{ABL}$, which disappears in the moment in which the leukemic cell population driven by native $\mathrm{BCR} / \mathrm{ABL}$ is suppressed by treatment.

How T315I is modulating the function of BCR/ABL is nearly unknown, mainly due to the fact that actually available models do not clearly reveal differences. Therefore we employed loss of function mutants of native $\mathrm{BCR} / \mathrm{ABL}$ in which $\mathrm{T} 315 \mathrm{I}$ restores at least parts of the
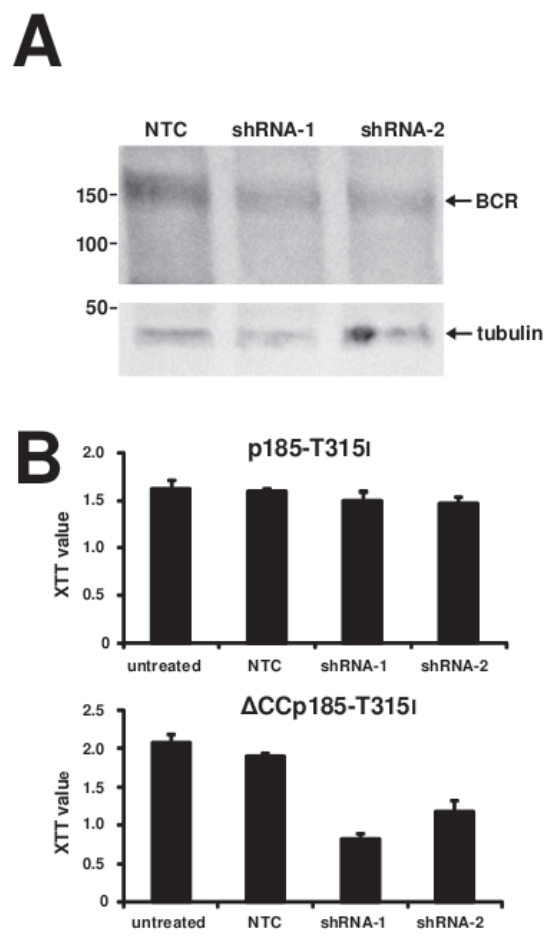

Figure 4: Role of endogenous BCR in the resistance of T315I mutation. 32D cells were transduced with the indicated transgenes and retransduced lentivirally with different shRNAs against endogenous BCR. A. Western blotting on lysates of 32D cells expressing the indicated transgenes using antibodies directed against BCR. Molecular mass references (KDa) are given and Tubulin was used as a loading control. B. For determining cells proliferation, XTT assay was performed. C. The apoptosis rate was determined by staining with 7-AAD. The data represent the mean and SD of three independent experiments. D. Western blotting on lysates of 32D cells expressing the indicated transgenes using antibodies directed against Erk1/2 and phosphorylated Erk1/2. Molecular mass references (KDa) are given. 
These different effects on proliferation are confirmed by the fact that the syngeneic CML-like disease induced by $\mathrm{BCR} / \mathrm{ABL}-\mathrm{T} 315 \mathrm{I}$ is significantly delayed as compared to that induced by native BCR/ABL [6].

The mechanism by which the presence of T315I leads to trans-phosphorylation of BCR by BCR/ABL loss of function mutants remains to be clarified. Similar to our findings on $\mathrm{p} 185^{B C R / A B L}, \mathrm{p} 210^{B C R / A B L}$ transactivates $\mathrm{BCR}$. In fact it co-precipitates $\mathrm{BCR}$ from $\mathrm{Ph}+$ cell lines and is a target for the $\mathrm{BCR} / \mathrm{ABL}$ tyrosine kinase activity [34, 38-41]. BCR/ABL phosphorylates BCR at tyrosine residues which leads to the inhibition of the BCR S/T kinase activity of BCR and thus may not only activate RAS-signaling but also revert the inhibitory effect of S-phosphorylated BCR on the BCR/ABL TK activity [39, 42].
Another important aspect of our study is the fact that we can now distinguish between features important for the mediation of factor independent growth and those important for the classical transformation potential. The combined deletion of the serine/threonine $(\mathrm{S} / \mathrm{T})$ and Grb-2 binding (Y177) domains completely abolished the transformation potential of p185 - T315 $\mathrm{I}^{B C R / A B L}$ was able to restore only factor independence but not full transformation potential indicating that it needs different domains for different phenotypes like factor independence and transformation potential which might be responsible for the additional oncogenic activity of T315.

In summary, our data show that T315I not only interferes with the affinity of ATP-analogs for the ABLkinase, but also conferring strong biological activity that seems to be related to the phosphorylation of endogenous

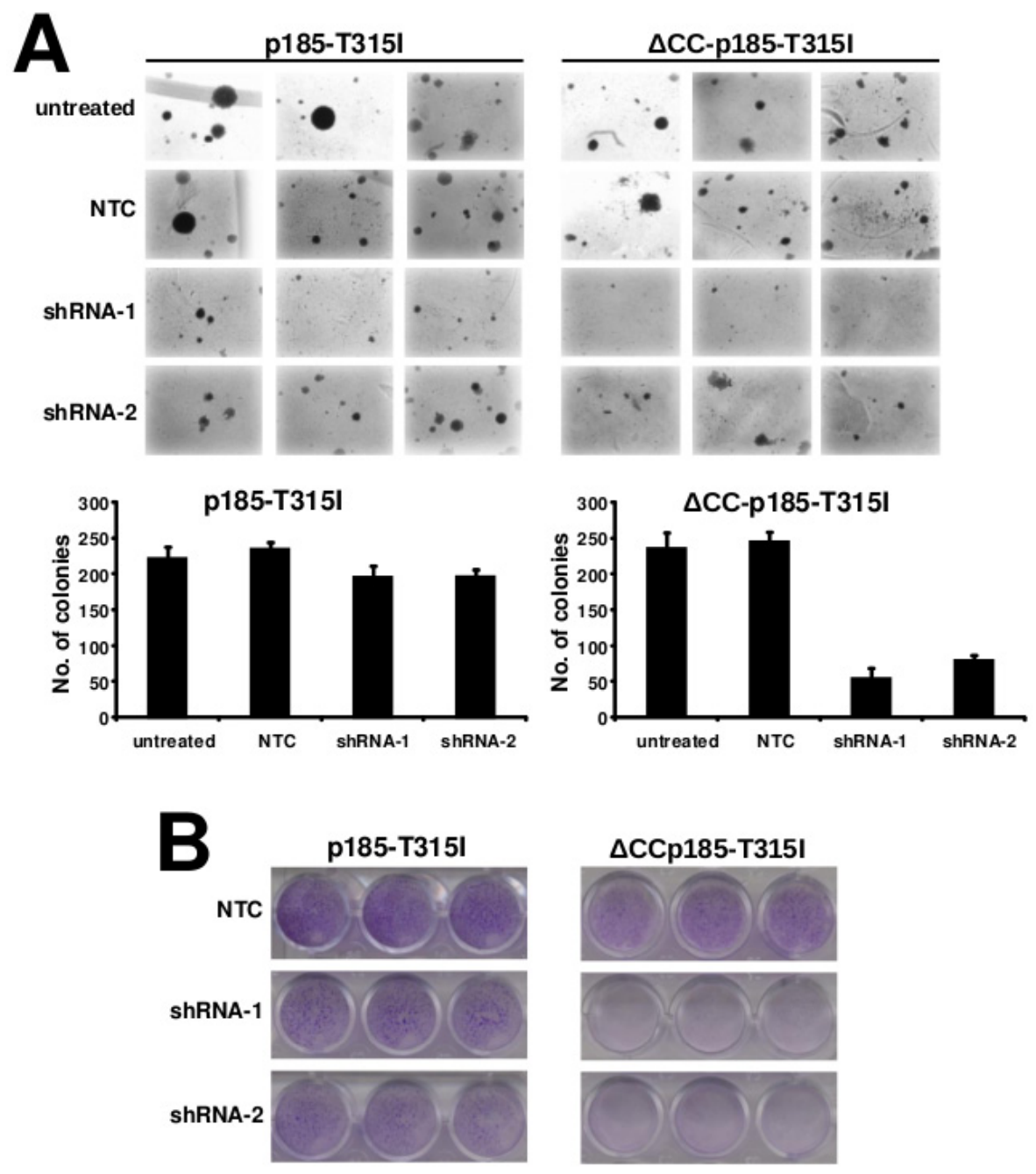

Figure 5: Role of endogenous BCR in the resistance of T315I mutation. For the determination for transformation assays, Rat-1 cells were retrovirally transduced with the indicated transgenes and retransduced lentivirally with different shRNAs against endogenous BCR. A. Colony formation - Rat-1 cells were retrovirally transduced with the indicated constructs and seeded at $5 \times 10^{3}$ cells/well in softagar in 6-well-plates. After 15 days, the colonies were counted and the means +/- SDS of triplicates of 2 representative experiments are given. B. Focus formation assay - $4 \times 10^{4}$ infected Rat-1 cells/well were plated in 24 -well-plates, grown for $72 \mathrm{~h}$ to confluence, and incubated for additional 12 days. The plates were then washed, dried, and stained with crystal violet. One representative of each of 3 experiments performed in triplicate is given (34x magnification). 
bcr. These findings introduce new approaches for the molecular therapy of patients harboring TKI-resistant $\mathrm{BCR} / \mathrm{ABL}$ mutations.

\section{MATERIALS AND METHODS}

\section{Plasmids}

The cDNAs encoding $\mathrm{p} 185^{B C R / A B L}, \mathrm{p} 185-\mathrm{T} 315$, their respective mutants lacking the $\mathrm{N}$-terminal $\mathrm{CC}$ domain ( $\triangle \mathrm{CC}$-p185 and $\triangle \mathrm{CC}-\mathrm{p} 185-\mathrm{T} 315 \mathrm{I})$, the ABL part of BCR/ABL (\#ABL and \#ABL-T315I), deletion mutants of putative $\mathrm{BCR}$ serine/threonine kinase domain $\mathrm{BCR}(1-$ 196)/ABL and BCR(1-196)/ABL-T315), the constructs with a direct fusion of the $\mathrm{CC}$-domain of $\mathrm{BCR}$ to the ABL-portion of BCR/ABL (BCC-ABL and BCC-ABLT315I), the p185-Y177F and p185-Y177F-T315I as well as the $\Delta$ CC-p185-Y177F and $\Delta$ CC-p185- Y177F-T315I and the related retroviral PINCO vectors have been previously described $[28,30]$. Short hairpin (sh) RNA sequences encoding inverted repeats of 21 nucleotides (nt) separated by a $10 \mathrm{nt}$ spacer were purchased from Sigma Aldrich (Steinheim, Germany). The inverted repeats corresponded to 2158-2179bp and 2602-2622bp, of the murine Bcr cDNA. All other constructs have been previously described [18].

\section{Cell lines}

32D cells were obtained from the German Collection of Microorganisms and Cell Cultures (DSMZ, Braunschweig, Germany) and maintained in RPMI-1640 medium supplemented with $10 \%$ fetal calf serum (FCS) (Invitrogen) containing $10 \mathrm{ng} / \mathrm{ml} \mathrm{IL-3} \mathrm{(Cell} \mathrm{Concepts,}$ Umkirch, Germany). Ecotropic Phoenix cells, 293T cells and Rat- 1 cells were cultured in DMEM supplemented with $10 \%$ FCS.

\section{Transformation assays}

Soft-agar and focus formation assays were performed using Rat-1 fibroblasts retrovirally transduced with PINCO vectors harboring native or mutant $\mathrm{p} 185^{B C R}$ ${ }^{A B L}$. Six-well plates were filled with DMEM supplemented with $10 \% \mathrm{FCS}$ and $0.5 \%$ bacto-agar (DIFCO Laboratories, Detroit, MI, USA). Then, $5 \times 10^{3}$ transduced Rat- 1 cells were suspended in 'top-agar' (DMEM supplemented with $10 \%$ FCS and $0.25 \%$ bacto-agar) and stacked in the wells. Colonies were counted after 15 days incubation. For focus-formation assays in a 24-well plate format, 4 x $10^{4}$ transduced Rat- 1 cells were plated per well. Foci were stained after 15 days using $1 \%$ crystal violet (SigmaAldrich).

\section{Retroviral and lentiviral infection and transfection}

Ecotropic retroviral supernatants were obtained as described earlier [30]. Lentiviral supernatant were obtained from $293 \mathrm{~T}$ cells transfeced with pLKO.1 encoding the desired shRNA, pCMVDR8.91 encoding gag and pol and pMD2.G encoding VSV-G pseudotype envelope protein. $1 \times 10^{5}$ target cells were plated onto retronectincoated (Takara-Shuzo, Shiga, Japan) 24-well-plates and exposed to the retroviral or lentiviral supernatant and were centrifuged at $2.200 \mathrm{rpm}$ for $45 \mathrm{~min}$ on $32^{\circ} \mathrm{C}$. The infection was repeated 3- 4 times and infection efficiency was measured after $48 \mathrm{~h}$ by determining the percentage of GFP positive cells by flow cytometry.

\section{Western blotting}

Western blot analyses were performed according to widely established protocols. The following antibodies were used: anti-ABL (a-ABL) Santa Cruz Biotechnology, Santa Cruz, CA, USA), anti-phosphorylated ABL specific for the phosphorylated tyrosine-residues 245 (a-pABL-Y245) (Upstate-Biotechnology, Lake Placid, NY, USA), anti-BCR (a-BCR) (Santa Cruz Biotechnology), anti-phosphorylated BCR-Y177 (a-p-BCR-Y177) (Cell Signaling, Boston, USA), anti-STAT5, anti phosphorylated STAT5 (Cell Signaling, Boston, MA, USA), anti-Erk1/2 and anti phosphorylated Erk1/2 (Cell Signaling, Boston, MA, USA). Blocking and antibody incubation were performed in 5\% low-fat dry milk.

\section{Proliferation and apoptosis assay}

Proliferation was assessed by using the XTT proliferation kit (Roche, Mannheim,Germany), according to the manufacturer's instructions. Apoptosis was measured by 7-AAD staining as described previously [18].

\section{AUTHOR CONTRIBUTIONS}

IH: collection and/or assembly of data, data analysis and interpretation; AR: collection and/or assembly of data, data analysis and interpretation; CO: collection and/or assembly of data, data analysis and interpretation, final approval of manuscript; MR: conception and design, collection and/or assembly of data, data analysis and interpretation, manuscript writing, financial support, final approval of manuscript; AAM: conception and design, collection and/or assembly of data, data analysis and interpretation, manuscript writing, final approval of manuscript. 


\section{CONFLICTS OF INTEREST}

No conflicts of interest to declare.

\section{REFERENCES}

1. Faderl S, Talpaz M, Estrov Z, O'Brien S, Kurzrock R and Kantarjian HM. The biology of chronic myeloid leukemia. N Engl J Med. 1999; 341:164-172.

2. Hantschel O. Structure, regulation, signaling, and targeting of abl kinases in cancer. Genes Cancer. 2012; 3:436-446. doi: 10.1177/1947601912458584.

3. Li S, Ilaria RL, Jr., Million RP, Daley GQ and Van Etten RA. The P190, P210, and P230 forms of the BCR/ABL oncogene induce a similar chronic myeloid leukemialike syndrome in mice but have different lymphoid leukemogenic activity. J Exp Med. 1999; 189:1399-1412.

4. Huettner CS, Zhang P, Van Etten RA and Tenen DG. Reversibility of acute B-cell leukaemia induced by BCRABL1. Nat Genet. 2000; 24:57-60.

5. Koschmieder S, Gottgens B, Zhang P, Iwasaki-Arai J, Akashi K, Kutok JL, Dayaram T, Geary K, Green AR, Tenen DG and Huettner CS. Inducible chronic phase of myeloid leukemia with expansion of hematopoietic stem cells in a transgenic model of BCR-ABL leukemogenesis. Blood. 2005; 105:324-334.

6. Mian AA, Rafiei A, Haberbosch I, Zeifman A, Titov I, Stroylov V, Metodieva A, Stroganov O, Novikov F, Brill B, Chilov G, Hoelzer D, Ottmann OG and Ruthardt M. PF114 , a potent and selective inhibitor of native and mutated $\mathrm{BCR} / \mathrm{ABL}$ is active against Philadelphia chromosomepositive $(\mathrm{Ph}+)$ leukemias harboring the T315I mutation. Leukemia. 2015; 29:1104-1114.

7. Cortes JE, Jones D, O'Brien S, Jabbour E, Ravandi F, Koller C, Borthakur G, Walker B, Zhao W, Shan J and Kantarjian H. Results of dasatinib therapy in patients with early chronic-phase chronic myeloid leukemia. J Clin Oncol. 2010; 28:398-404.

8. Hughes TP, Hochhaus A, Branford S, Muller MC, Kaeda JS, Foroni L, Druker BJ, Guilhot F, Larson RA, O’Brien SG, Rudoltz MS, Mone M, Wehrle E, Modur V, Goldman JM, Radich JP, et al. Long-term prognostic significance of early molecular response to imatinib in newly diagnosed chronic myeloid leukemia: an analysis from the International Randomized Study of Interferon and STI571 (IRIS). Blood. 2010; 116:3758-3765.

9. Cortes JE, Kantarjian HM, Brummendorf TH, Kim DW, Turkina AG, Shen ZX, Pasquini R, Khoury HJ, Arkin S, Volkert A, Besson N, Abbas R, Wang J, Leip E and Gambacorti-Passerini C. Safety and efficacy of bosutinib (SKI-606) in chronic phase Philadelphia chromosomepositive chronic myeloid leukemia patients with resistance or intolerance to imatinib. Blood. 2011; 118:4567-4576.

10. Giles FJ, Kantarjian HM, le Coutre PD, Baccarani M,
Mahon FX, Blakesley RE, Gallagher NJ, Gillis K, Goldberg SL, Larson RA, Hochhaus A and Ottmann OG. Nilotinib is effective in imatinib-resistant or -intolerant patients with chronic myeloid leukemia in blastic phase. Leukemia. 2012; 26:959-962.

11. Hoglund M, Sandin F, Hellstrom K, Bjoreman M, Bjorkholm M, Brune M, Dreimane A, Ekblom M, Lehmann S, Ljungman P, Malm C, Markevarn B, Myhr-Eriksson K, Ohm L, Olsson-Stromberg U, Sjalander A, et al. Tyrosine kinase inhibitor usage, treatment outcome, and prognostic scores in CML: report from the population-based Swedish CML registry. Blood. 2013; 122:1284-1292.

12. Cortes J, Jabbour E, Kantarjian H, Yin CC, Shan J, O'Brien S, Garcia-Manero G, Giles F, Breeden M, Reeves N, Wierda WG and Jones D. Dynamics of BCR-ABL kinase domain mutations in chronic myeloid leukemia after sequential treatment with multiple tyrosine kinase inhibitors. Blood. 2007; 110:4005-4011.

13. Shah NP, Skaggs BJ, Branford S, Hughes TP, Nicoll JM, Paquette RL and Sawyers CL. Sequential ABL kinase inhibitor therapy selects for compound drug-resistant BCRABL mutations with altered oncogenic potency. J Clin Invest. 2007; 117:2562-2569.

14. O'Hare T, Walters DK, Stoffregen EP, Jia T, Manley PW, Mestan J, Cowan-Jacob SW, Lee FY, Heinrich MC, Deininger MW and Druker BJ. In vitro activity of Bcr-Abl inhibitors AMN107 and BMS-354825 against clinically relevant imatinib-resistant Abl kinase domain mutants. Cancer Res. 2005; 65:4500-4505.

15. Adrian FJ, Ding Q, Sim T, Velentza A, Sloan C, Liu Y, Zhang G, Hur W, Ding S, Manley P, Mestan J, Fabbro D and Gray NS. Allosteric inhibitors of Bcr-abl-dependent cell proliferation. Nat Chem Biol. 2006; 2:95-102.

16. O'Hare T, Eide CA and Deininger MW. Bcr-Abl kinase domain mutations, drug resistance, and the road to a cure for chronic myeloid leukemia. Blood. 2007; 110:22422249.

17. Beissert T, Hundertmark A, Kaburova V, Travaglini L, Mian AA, Nervi $\mathrm{C}$ and Ruthardt M. Targeting of the N-terminal coiled coil oligomerization interface by a helix-2 peptide inhibits unmutated and imatinib-resistant BCR/ABL. Int J Cancer. 2008; 122:2744-2752.

18. Mian AA, Oancea C, Zhao Z, Ottmann OG and Ruthardt M. Oligomerization inhibition, combined with allosteric inhibition, abrogates the transformation potential of T315Ipositive BCR/ABL. Leukemia. 2009; 23:2242-2247.

19. O'Hare T, Shakespeare WC, Zhu X, Eide CA, Rivera VM, Wang F, Adrian LT, Zhou T, Huang WS, Xu Q, Metcalf CA, 3rd, Tyner JW, Loriaux MM, Corbin AS, Wardwell S, Ning Y, et al. AP24534, a pan-BCR-ABL inhibitor for chronic myeloid leukemia, potently inhibits the T315I mutant and overcomes mutation-based resistance. Cancer Cell. 2009; 16:401-412.

20. Cortes JE, Kantarjian H, Shah NP, Bixby D, Mauro MJ, Flinn I, O’Hare T, Hu S, Narasimhan NI, Rivera VM, 
Clackson T, Turner CD, Haluska FG, Druker BJ, Deininger MW and Talpaz M. Ponatinib in refractory Philadelphia chromosome-positive leukemias. N Engl J Med. 2012; 367:2075-2088.

21. Cortes JE, Kim DW, Pinilla-Ibarz J, le Coutre P, Paquette R, Chuah C, Nicolini FE, Apperley JF, Khoury HJ, Talpaz M, DiPersio J, DeAngelo DJ, Abruzzese E, Rea D, Baccarani M, Muller MC, et al. A phase 2 trial of ponatinib in Philadelphia chromosome-positive leukemias. N Engl J Med. 2013; 369:1783-1796.

22. Schindler T, Bornmann W, Pellicena P, Miller WT, Clarkson B and Kuriyan J. Structural mechanism for STI571 inhibition of abelson tyrosine kinase. Science. 2000; 289:1938-1942.

23. Corbin AS, Buchdunger E, Pascal F and Druker BJ. Analysis of the structural basis of specificity of inhibition of the Abl kinase by STI571. J Biol Chem. 2002; 277:3221432219 .

24. Weisberg E, Manley PW, Breitenstein W, Bruggen J, Cowan-Jacob SW, Ray A, Huntly B, Fabbro D, Fendrich G, Hall-Meyers E, Kung AL, Mestan J, Daley GQ, Callahan L, Catley L, Cavazza C, et al. Characterization of AMN107, a selective inhibitor of native and mutant Bcr-Abl. Cancer Cell. 2005; 7:129-141.

25. Tokarski JS, Newitt JA, Chang CY, Cheng JD, Wittekind M, Kiefer SE, Kish K, Lee FY, Borzillerri R, Lombardo LJ, Xie D, Zhang Y and Klei HE. The structure of Dasatinib (BMS-354825) bound to activated ABL kinase domain elucidates its inhibitory activity against imatinib-resistant ABL mutants. Cancer Res. 2006; 66:5790-5797.

26. Pricl S, Fermeglia M, Ferrone M and Tamborini E. T315Imutated $\mathrm{Bcr}-\mathrm{Abl}$ in chronic myeloid leukemia and imatinib: insights from a computational study. Mol Cancer Ther. 2005; 4:1167-1174.

27. Griswold IJ, MacPartlin M, Bumm T, Goss VL, O'Hare T, Lee KA, Corbin AS, Stoffregen EP, Smith C, Johnson K, Moseson EM, Wood LJ, Polakiewicz RD, Druker BJ and Deininger MW. Kinase domain mutants of Bcr-Abl exhibit altered transformation potency, kinase activity, and substrate utilization, irrespective of sensitivity to imatinib. Mol Cell Biol. 2006; 26:6082-6093.

28. Mian AA, Schull M, Zhao Z, Oancea C, Hundertmark A, Beissert T, Ottmann OG and Ruthardt M. The gatekeeper mutation T315I confers resistance against small molecules by increasing or restoring the ABL-kinase activity accompanied by aberrant transphosphorylation of endogenous BCR, even in loss-of-function mutants of BCR/ ABL. Leukemia. 2009; 23:1614-1621.

29. McWhirter JR, Galasso DL and Wang JY. A coiledcoil oligomerization domain of Bcr is essential for the transforming function of Bcr-Abl oncoproteins. Mol Cell Biol. 1993; 13:7587-7595.

30. Beissert T, Puccetti E, Bianchini A, Guller S, Boehrer S, Hoelzer D, Ottmann OG, Nervi C and Ruthardt M.
Targeting of the N-terminal coiled coil oligomerization interface of $\mathrm{BCR}$ interferes with the transformation potential of BCR-ABL and increases sensitivity to STI571. Blood. 2003; 102:2985-2993.

31. Guo XY, Cuillerot JM, Wang T, Wu Y, Arlinghaus R, Claxton D, Bachier C, Greenberger J, Colombowala I and Deisseroth AB. Peptide containing the BCR oligomerization domain (AA 1-160) reverses the transformed phenotype of p210bcr-abl positive 32D myeloid leukemia cells. Oncogene. 1998; 17:825-833.

32. Zhang X, Subrahmanyam R, Wong R, Gross AW and Ren $\mathrm{R}$. The NH(2)-terminal coiled-coil domain and tyrosine 177 play important roles in induction of a myeloproliferative disease in mice by Bcr-Abl. Mol Cell Biol. 2001; 21:840853.

33. Pfeifer H, Lange T, Wystub S, Wassmann B, Maier J, Binckebanck A, Giagounidis A, Stelljes M, Schmalzing M, Duhrsen U, Wunderle L, Serve H, Bruck P, Schmidt A, Hoelzer D and Ottmann OG. Prevalence and dynamics of bcr-abl kinase domain mutations during imatinib treatment differ in patients with newly diagnosed and recurrent bcrabl positive acute lymphoblastic leukemia. Leukemia. 2012; 26:1475-1481.

34. Pendergast AM, Quilliam LA, Cripe LD, Bassing CH, Dai Z, Li N, Batzer A, Rabun KM, Der CJ, Schlessinger J and et al. BCR-ABL-induced oncogenesis is mediated by direct interaction with the SH2 domain of the GRB-2 adaptor protein. Cell. 1993; 75:175-185.

35. Modi H, Li L, Chu S, Rossi J, Yee JK and Bhatia R. Inhibition of Grb2 expression demonstrates an important role in BCR-ABL-mediated MAPK activation and transformation of primary human hematopoietic cells. Leukemia. 2011; 25:305-312.

36. Serrano M, Lin AW, McCurrach ME, Beach D and Lowe SW. Oncogenic ras provokes premature cell senescence associated with accumulation of p53 and p16INK4a. Cell. 1997; 88:593-602.

37. Lin AW, Barradas M, Stone JC, van Aelst L, Serrano M and Lowe SW. Premature senescence involving p53 and p16 is activated in response to constitutive MEK/MAPK mitogenic signaling. Genes Dev. 1998; 12:3008-3019.

38. Liu J, Campbell M, Guo JQ, Lu D, Xian YM, Andersson $\mathrm{BS}$ and Arlinghaus RB. BCR-ABL tyrosine kinase is autophosphorylated or transphosphorylates P160 BCR on tyrosine predominantly within the first BCR exon. Oncogene. 1993; 8(1):101-109.

39. Liu J, Wu Y, Ma GZ, Lu D, Haataja L, Heisterkamp N, Groffen $\mathrm{J}$ and Arlinghaus RB. Inhibition of Bcr serine kinase by tyrosine phosphorylation. Mol Cell Biol. 1996; 16:998-1005.

40. Lu D, Liu J, Campbell M, Guo JQ, Heisterkamp N, Groffen J, Canaani E and Arlinghaus R. Tyrosine phosphorylation of P160 BCR by P210 BCR-ABL. Blood. 1993; 82:12571263. 
41. Puil L, Liu J, Gish G, Mbamalu G, Bowtell D, Pelicci PG, Arlinghaus R and Pawson T. Bcr-Abl oncoproteins bind directly to activators of the Ras signalling pathway. EMBO J. 1994; 13:764-773.

42. Liu J, Wu Y and Arlinghaus RB. Sequences within the first exon of BCR inhibit the activated tyrosine kinases of c-Abl and the Bcr-Abl oncoprotein. Cancer Res. 1996; 56(22):5120-5124. 